\title{
The Social Foundations of the Bureaucratic Order
}

\author{
Jannis Kallinikos
}

London School of Economics

\begin{abstract}
This article views the bureaucratic form of organization as both an agent and an expression of key modern social innovations that are most clearly manifested in the non-inclusive terms by which individuals are involved in organizations. Modern human involvement in organizations epitomizes and institutionally embeds the crucial yet often overlooked cultural orientation of modernity whereby humans undertake action along well-specified and delimited paths thanks to their capacity to isolate and suspend other personal or social considerations. The organizational involvement of humans qua role agents rather than qua persons helps unleash formal organizing from being tied to the indolence of the human body and the languish process of personal or psychological reorientation. Thanks to the loosening of these ties, the bureaucratic organization is rendered capable to address the shifting contingencies underlying modern life by reshuffling and re-assembling the roles and role patterns by which it is made. The historically unique adaptive capacity of bureaucracy remains though hidden behind the ubiquitous presence of routines and standard operating procedures -requirements for the standardization of roles- that are mistakenly exchanged for the essence of the bureaucratic form.
\end{abstract}

The reigning myth today is that the evils of society can all be understood as evils of impersonality, alienation, and coldness. The sum of these three is an ideology of intimacy...[that] transmutes political categories into psychological categories.

Richard Sennett, The Fall of Public Man

\section{The End of the Bureaucratic Age}

Popular belief associates bureaucracy with routine, initiative stifling office work and an introvert organizational culture of rigid administrative procedures and redundant complexity. Although social reality seldom appears as simple as the popular image wants it to be, this oversimplified picture of the bureaucratic form of organization has nevertheless been widely shared and persistent. Critical humanism and artistic aversion $^{1}$ of bureaucratic systems have allied with left-inspired criticism of the organiza-

\footnotetext{
${ }^{1}$ The novels of Franz Kafka, the Trial and the Tower stand here as major examples. Though perhaps visionary images of some terrifying aspects of modernity in general, the novels can certainly be read as metaphoric descriptions of bureaucratic institutions. The artistic criticism against state administration is expressed well in the spirit of Dadaism and Surrealism but such a suspicious attitude towards large administrative systems can be re-encountered across most artistic movements throughout the last century. It is important to keep that in mind to understand the neo-romantic elements of the current criticism of bureaucracy.
} 
tional practices of capitalism or statism to re-enhance the image of bureaucracy as an institution that degrades human dignity and perpetuates social inequalities (e.g. Adorno and Horkeimer, 1972/1937; Castoriadis, 1985, 1987; Marcuse, 1955). For quite different, though not unrelated, reasons bureaucracy has been faced with distrust and distaste by liberal neo-classical and post neo-classical economics. While formal organization has occasionally been seen as a reasonable governance alternative to the market (Arrow, 1974; Coase, 1937; Williamson, 1975), the dominant picture in economics has tended to view bureaucracy as an institution that inhibits economic growth and threatens individual liberty (see, e.g. Hayek, 1960).

In recent years, bureaucracy has repeatedly received a severe verdict that predicts its unmistakable demise. Another basic form of organization often referred to as the entrepreneurial or network-shaped organization (e.g. Heckscher and Donnellon, 1994; Rifkin, 2000) is said to be pushing bureaucracy to the margins of the contemporary organizational and economic scene. However, apart from a few studies outside the immediate realm of management and organization theory (e.g. Castells, 1996, 2001; Carnoy, 2000; Fukuyama, 1997), the claim concerning the demise of bureaucracy has not been supported by the systematic investigation of the organizational and occupational order of modernity. As a matter of fact there has never been a serious intention in the fad-driven mainstream management discipline (a major exponent of the bureaucratic demise) of systematically comparing bureaucracy with alternative forms of organization.

To the serious student of organization forms, the juxtaposition of the bureaucratic and entrepreneurial forms of organization does not hold (du Gay, 1994, 2000). We do hope to show in this article that the entrepreneurial and managerial critique of bureaucracy is based on oversimplified and stylized images of the bureaucratic form of organization. Most significantly, such a critique is marked by an astonishingly naïve functionalism devoid of any historical awareness. These limitations contribute to the misinterpretation of bureaucracy through the overrepresentation of secondary characteristics of the organizational order underlying modernity. Management "theory" has often given proof of surprisingly poor historical awareness but the assertion of organizational change, profound enough to justify the end of bureaucratic age, makes such an inadequacy woefully evident. Neither bureaucracy nor its asserted alternatives can properly be understood unless modernity and the social and organizational innovations it has brought about are sufficiently appreciated.

Despite, however, the oversimplified character of the discourse concerning the end of the bureaucratic age, it is crucial not to lose sight of the multifaceted economic, technological and social changes to which such a discourse is but one symptom. Such changes are associated with the diffusion of values, orientations or life styles that in- 
creasingly reflect the culture of individualism and the decline of legitimacy of public institutions (see, e.g. Beck, 1992, 2000; Sennett, 1992). Coupled with globalization, the weakening of the nation state and the rapid growth of information and communication technologies, the culture of individualism keeps on redefining core characteristics of modernity. Though these developments remain far from being crystallized, there is indeed some evidence to suggest that current socio-cultural and technological changes converge to the redrawing of the prevailing boundaries of the private and public world, work from leisure, family and community. ${ }^{2}$

Under these conditions, the very forms by which individuals have traditionally been tied to social institutions are bound to change (Beck, 1992; Baumann, 1992, Sennett, 1992, 2000). New forms of individual involvement in organizations (e.g. flexible and temporary forms of employment) develop to accommodate the shifts in social institutions, values and life styles mentioned above. At the same time information and communication technologies become an important agent of organizational and occupational change (Castells, 1996, 2001; Rifkin, 1995, 2000). The precise ways, though, by which organization forms are connected to these developments remain a contested terrain. Neither the organizational forms nor the mechanisms that bring them about are sufficiently studied or clear. The appreciation of the impact of these changes on the prevailing forms of organization would seem to require the serious reconsideration of the social institution of bureaucracy in ways that step beyond stereotyped images of it.

Let it be clear that the critical attitude vis-à-vis the claims that announce the demise of bureaucracy and the emergence of post-bureaucratic forms is not prompted by any dedicated commitment to the bureaucratic form of organization. The author neither condemns nor supports bureaucracy. Rethinking the foundations of bureaucracy serves the purpose of disclosing the social, cultural and economic roots of this institution and appreciating its limits against the background of a wider historical understanding. Undeniably, bureaucracy has entertained a number of tensions, most vividly shown in the contrast between the ideals of justice, meritocracy and egalitarianism by which it has been legitimized and the centralized and often awful practices with which it has been associated.

The article is structured in the following way. Next section takes up the issue of rule-bound behaviour that is often seen as the epitome of bureaucracy. It shows that standardization is a ubiquitous aspect of contemporary organizations that contrasts sharply with the assumed malleability and flexibility of post-bureaucratic organizing,

\footnotetext{
${ }^{2}$ Sennett (1992) suggests that the decline of the public world is a process that has been in the making for quite a long time. The roots of current developments, he claims, can be traced back to the nineteenth century. A similar, though differently, motivated claim can be extracted from Hannah Arendt's influential book "The Human Condition".
} 
calling for the careful reconsideration of the bureaucratic form. The following section undertakes precisely that task. Bureaucracy is identified with the non-inclusive coupling of the individual to the organization consequent upon the separation of the role from the person. On the basis of this claim, the article ventures to dissociate bureaucracy from the dominant connotation of an inflexible and rigid form. It shows that the non-inclusive modulation of the individual organization relationship makes bureaucracy the first and as yet sole organization form in which individuals are tied to organizations in selective, mobile and reversible terms. Such terms give the bureaucratic organization the possibility of addressing emerging contingencies. The final section of the article attempts to show that the non-inclusive involvement of individuals into organizations is the primary matrix of relations out of which other derivative characteristics, often taken as the epitome of bureaucracy, such as standardization and centralization, emerge. The article ends with a few concluding remarks.

\section{The Ubiquitous Character of Standardization}

Standard conceptions of bureaucracy reflecting the Weberian legacy consider this organization form as a major social innovation, essential to the expansion of industrial capitalism and the embeddedness of crucial social and economic goals or ideals such as progress, growth, meritocracy and egalitarianism. On this view, bureaucracy coincides with the advent of modernity, it is part and parcel of it (Gellner, 1983, 1996; Luhmann, 1982, 1995; Seyer, 1991). In organization studies, though, as Clegg (1994) has observed, the term has been used in a narrower fashion. Organization theorists defined bureaucracy in terms of a limited number of key characteristics and sought to explore empirically the degree to which these characteristics were present in various organizations. According to such an understanding of bureaucracy, an organization could emerge as more or less bureaucratic, depending on the intensity by which the key characteristics of standardization, formalization, centralization and role and functional specialization were governing its operations (see, e.g., Hall, 1982; Pugh et al., 1963, 1968; Scott, 1981).

A reinterpretation of these studies suggests that the four or five dimensions used to describe the bureaucratic principles of organization could collapse into hierarchy and rule-bound behaviour as the epitomes of the bureaucratic form of organization. In one sense, rule-bound behaviour conveys even more than hierarchy the traditional understanding of the bureaucracy as a system of routines and standard operating procedures (Perrow, 1986). Rule bound behaviour is expressed in an elaborate social edifice of rules, routines and formal role systems stipulating job positions, duties and jurisdictions and regulating interaction patterns. Rule-bound behaviour has often been seen to be at the heart of the behavioural mechanics governing bureaucracy. The 
popular and artistic distaste for bureaucracy derives by and large from this alleged depersonalized functioning of formal organizations.

However, the historical background of the social relations out of which bureaucracy emerged suggests some important qualifications. Rule bound behaviour was fashioned to accommodate the functioning of modern organizations whose operations could not any longer anchored in the normative certainty of gemeinschaft. Being active on a spatial and temporal scale that extended far beyond the limited world of premodern communities, modern organizations needed both the legitimacy and new principles for controlling their operations. The construction of formal role systems for regulating human behaviour in organizations emerged as a historical innovation, essential in sustaining the egalitarian ethos of modern society. Formal role systems provide transparent motives and legible behaviour, on the basis of which one can decide whether citizens are treated equally and the employees of the organization protected from any abuse or arbitrary exercise of power (Perrow, 1986). By the same token, the bracketing of personal goals and the imposition of a formal order reflect the awareness that the pursuit of personal ends within the context of an organization may well undermine the goals and the adequate functioning of an organization (du Gay, 1994, 2000). The institutionalization of expectations and action patterns coinciding with rule-bound behaviour were thus an essential means for avoiding haphazard initiatives and opportunism, and improving the performance of public organizations.

Depersonalized behaviour is obviously not limited to public organizations. Although it may have been originally occasioned by major ideals of the emerging bourgeois society that were socially embedded through precisely the adequate functioning of state or public bureaucracies, the bureaucratic standardization of behaviour describes the entire organizational landscape of modernity. In one form or another, depersonalized conduct has been made to an indispensable principle of all formal organizing in modernity. It has been applied with even greater severity in private firms and industrial organizations, where the design of jobs and the systems of surveillance tied to them emerged as the outcome of the relentless drive towards cost reduction, achieved through minute division of labour and economies of scale (Chandler, 1977). Rather than simply regulating behaviour, industrial organizations sought to regulate even the minutest details of workers' bodily movements (Braverman, 1974; Noble, 1984). Standardization in that sense has come close to betray the very ideals with which it has been associated. The inhuman, sometimes brutal, relations that prevailed in the industrial factories, in some cases as late as at the break of the Second World War, are indeed hard to reconcile with the ideals of liberty and justice.

Managerialist thinking easily relegates the job designing principles of industrial capitalism to the past, assuming that they are increasingly surpassed by important 
developments in the market environment and the technological infrastructure of production (Womack and Jones, 1996). It would be indeed difficult to deny the crucial organizational importance of major economic and technological innovations. Contemporary technology, in particular, has through extended automation changed significantly the conditions of production in industrial firms and other contexts of economic activity (Kallinikos, 2001). However, the status of these changes at the shop floor of the industrial factory and the outcome of these developments for the issue of behavioural mechanics that concerns us here are not entirely clear. There exist a number of studies to suggest a rather mixed and at times negative picture of recent trends, indicating greater control of employees, intensification of work (Kling, 1996; Zuboff, 1988) and novel forms of alienation (Carnoy, 2000; Harisson, 1994; Murray et al., 2002; Sennett, 2000).

Computer and information technologies do not make up an unequivocal ally to flexible patterns of behaviour, as the exponents of the post-bureaucratic or entrepreneurial form of organization often assume (Kallinikos 1998). The expanding organizational involvement of software packages might indeed contribute to the standardization of behaviour. Software packages are currently major means for structuring and organizing work in contemporary organizations. They are most of the times conceived and constructed by specialized software developing companies, in contexts other than those they are called upon to monitor. The construction of software packages by specialized organizations indicates that they are initially responses to abstract definitions of problems. Without this requirement the very development of programs would be impossible in the first place (Simon, 1969).

The increasing organizational involvement of de-contextualized systems of managing and monitoring information and the requirements of cross-contextual information comparability impose standardization in the form of a quasi-universal language of information processing. Undeniably, the introduction of software packages into organizations is a complex socio-technical process that involves deliberate and haphazard modifications. It is well known that software packages can be reconfigured to fit the demands of specific contexts or used in ways that were never thought of at the very moment of their inception (Ciborra, 2000). Yet the very substratum of software packages that reflects the logicist premises on which they are built and the cognitive mechanics of symbol processing cannot be undone (Lackoff, 1995) by reconfiguring or resisting the use and functionality of particular software packages. But even at the more macroscopic level of everyday work, software packages punctuate experience and impose uniformity through:

- The standardized definition of problems (or problem spaces).

- The specification of the tasks that the problem thus defined involves. 
- The delineation of the procedural steps necessary to enact the logic of the software package (Kling 1996; Zuboff 1988).

Software packages are thus far from innocent means that support organizational operations. Rather, the three categories of effects stated above and the very cognitive foundations of software packages suggest that they hypostatize both meaning and action patterns. As perhaps any technology, software packages embody human experience, inviting particular modes of understanding and action that involve both the framing of the reality to be addressed, the determination of particular tasks and their sequential patterning. It is not by accident that information technology has now and then being considered as a mechanized contemporary alternative to the rule-bound behaviour of bureaucracy (e.g. Beniger, 1986).

Information systems undeniably promote standardization, even though homogeneity and uniformity may not be their sole affects. Current technology also enables a form of bricolage, exercised upon the huge number of information items and applications that constitute the landscape of most contemporary organizations (Ciborra, 2000). Software packages are in this way pregnant with various option possibilities that are produced by the play of permutations to which the many information items underlying them can enter. Also, the development of links across organizations allows for the relatively easy crossing of institutional boundaries in ways that may promote alternative models of individual and organizational action (Castells, 2001). But these rather obvious effects should not hide the deep standardization of cognition and action, accomplished by the diffusion and organizational involvement of information systems. Standardization goes underneath the surface flexibility enabled by current technology. It involves uniform procedures for problem definition and problem solving, imposed by automated models of cognition, as described above. It even entails the standardization of interfaces, protocols and various hardware and software components (Hanseth, 2000). The ubiquitous character of standardization in contemporary life provides evidence in support of the claim that it cannot be made the exclusive arbiter of the bureaucratic form of organization.

The evidence that standardization represents a viable and widely diffused job and process design methodology is furthermore supported by the rapid and impressive diffusion of the standards of the ISO series during the last two decades. It is obvious that the ISO standards lead to rule-bound and standardized patterns of behaviour. But standardization represents an ideal even in models of management underlying the entrepreneurial or network form of organization like for instance Total Quality Management (TQM). Product quality in TQM models is by and large defined in terms of its capacity to conform to a set of pre-specified standards. Therefore, the careful de- 
sign of these standards as well as the standardization of the process by which the product (or a service) is produced represent the fundamental requirements for achieving this goal. Indeed, TQM is a methodology of predictability, achieved through the minute description of various work tasks and processes and carried out in ways that demand active involvement of the employees of the organization throughout the production process (see, e.g. Womack and Jones, 1996).

Standardization of behaviour seems furthermore to represent a viable job design methodology in types or organizations that may be intuitively thought to represent a contrast to the popular image of rigid bureaucracies. Everyday observations suggest that organizations that are commonly assumed to be market-driven and customer targeting, like for instance airlines, banks or insurance companies, use standardized and largely stylized modes of conduct in abundance. Standardized behaviour not only continues to play a crucial role in many types of service organizations but some service, "consumer-responding" organizations have extended the regulative domain of standardization, allowing it to shape such spontaneous behaviours such as smiling, wording, eye contact and other minute aspects of human conduct.

In sum, this brief review and re-contextualization of recent developments does not lend immediate support to the liberal neo-romanticism of individual creativity and initiative taking, following the decline of bureaucracy. Standardization is as ubiquitous as the very changes that may be taken to suggest the emergence of new forms of organization. There is a need, therefore, to turn to a more thorough and systematic study of bureaucracy. The current controversy between bureaucratic forms of organization and its asserted alternatives must be placed in a wider and coherent framework that may give it its appropriate meaning.

\section{The Social Innovations of Bureaucracy}

The bureaucratic form of organization is both the outcome of the wider social and cultural orientations of modernity and a major agent for institutionally embedding these orientations. The contribution bureaucracy has historically made to this goal is most clearly manifested on the highly distinctive mode by which it came to regulate the individual-organization relationship. For first time in history, an organization form systematically decoupled the terms by which individuals were tied to organizations from concrete persons (Weber, 1970, 1978). Supported by the wider anthropological orientations of modernity, bureaucracy dissociated the organizational role taking from social position and the experiential totality that is commonly associated with the personality or the particular mode of being of a person. It thus inaugurated a new structural principle by which individuals have come to be tied to organizations in terms other than inclusive. Non-inclusiveness implies that individuals are not contained in organi- 
zations and these last are not made of the aggregate of persons but of roles and the patterns brought about by the interdependence of roles (Luhmann, 1995; Tsivacou, 1997). The inescapable corporeality of the human condition should not be taken to imply that individuals enter organizations in their full-blown cognitive, emotional, and social complexity.

It is crucial to appreciate the distinctive status of relations out of which bureaucracy emerges as the modern form of organization. The role, not the person, constitutes the fundamental structural and behavioural element of modern formal organizing. Organizations are not made of individuals distributed over a complex landscape of job positions but of patterns built by those abstract operational requirements we call roles. Roles are enacted by the intrinsically modern capacity of contemporary humans to systematically and consistently suspend all other personal or organizational aspects that do not bear upon the role and to undertake action (e.g. machine operator, accountant, salesman, secretary etc.) along delimited and well-specified paths. The living energy and the general communicative capacity of humans are essential resources for organizations (as it is for all social life) but this should not lead one to assume that formal organizations are made of individuals qua persons.

Bureaucracy thus introduces an abstract conception of work as a set of delimited behavioural choices (i.e. duties) that can be dissociated from the totality of the life world and from the distinctive mode of being of every person. A major objective and an important consequence of the bureaucratic modulation of the individualorganization relationship is that individuals join the organization on the basis of considerations that relate to their ability to assume a role, i.e. on the basis of merits provided by education, working experience, etc. At the same time, other aspects of an individual's life are severed from bureaucratic regulation. The non-inclusive involvement of individuals in organizations is sustained by the adequate differentiation of both individual and social life. That is, the characteristics that derive from education, professional specialization and working experience cover only a part (admittedly a very important one) of the totality of an individual's roles and projects. In the social context of modernity, other organizations and institutions that are clearly and unambiguously differentiated from work organizations, e.g. family and community, represent a crucial outlet of the individual's interests and activities. The segmentation of life into separate and relatively independent spheres is an essential requirement for the forms of human involvement upon which bureaucracy is predicated (Kallinikos, 2003).

The bureaucratic form and the non-inclusive way of modulating the individual-organization relationship coincided with the gradual dissolution of class stratification and the immobile, hereditary social relations characteristic of the late feudal 
world (Gellner, 1983, 1996; Luhmann, 1982, 1995, 1996). Bureaucracy emerged as the dominant modern organization form out of the overall rational and functional preoccupations of modernity. However, the novel way of orchestrating the individualorganization relationship represented itself an important vehicle for constructing a new organizational form, premised on universalism and meritocracy as major principles for realizing and embedding the bourgeois ideals of individual liberty and justice (du Gay, 2000). By standardizing the requirements of role performance and formalizing the process of role taking, the bureaucratic organization became the vehicle through which jobs became potentially available to anyone that fulfilled the requirements of job specification. It is through the very separation of the role from the person that such an availability can be rendered possible and a labour contract be signed that make the terms of the agreement legible and law enforceable (Weber, 1947, 1970, 1978).

Bureaucracy and modernity are therefore inextricably bound up with one another. Bureaucracy is the organization form of modernity. It is closely associated with the overall cultural orientations of modern man, the social mobility that coincided with the gradual dissolution of pre-modern stratification, and the burgeoning bourgeois ideals of individual freedom and justice, which it helped itself to embed. In this respect, bureaucracy contrasts sharply with pre-modern forms of organizing that relied by and large on the principle of inclusion for regulating the relationship of people to organizations. The differentiation of personal, social and working aspects of identity was elementary in the agricultural, feudal world. As a consequence these aspects of people's life could not be separated from one another, as it is the case in modernity (Gellner, 1983). In the pre-modern, segmentary societies, the social position -defined by a fixed and basically immobile social stratification regulated and reproduced as a rule by hereditary relations - determined by and large the working identity of people. The relatively open space of bourgeois democracy and the social mobility associated with it formed the basic conditions for the emergence of the organizational form that Weber came gradually to designate as bureaucracy.

The far reaching significance of modulating the individual-organization relationship in terms other than inclusive emerges clearly in the background of the comparison of bureaucracy with the organizational form that Goffman (1961) once called total organizations, i.e. mental hospitals, prisons, monasteries, army barracks, religious sects, etc. In contrast to the non-inclusive coupling of the individual to the organization underlying bureaucracy, total organizations are based on the structural principle of inclusion. Individuals are contained in the organization, they are in other words "inmates". Total organizations impose their austere order on the entire personality of their members. They do not distinguish between personality and collective. 
The term individual, as we know it, is alien to this form of organization. Total organizations thus provide an instructive contrast to bureaucracy. The latter may owe part of its administrative practices to the meticulous discipline worked out in the austere world of monasteries (Mumford, 1934), yet an abysmal chasm separates the bureaucratic organization from monasteries or other total organizations. Such a chasm is precisely produced by the non-inclusive, conspicuously modern and abstract mode of regulating the individual-organization relationship.

The profound differences separating inclusive and non-inclusive modes of regulating the individual-organization relationship are perhaps obscured by the impressive diffusion of the bureaucratic principles and the withdrawal of total organizations to the fringes of modern everyday social encounters. Being the "normal" yardstick of functional ability and institutional legitimacy, bureaucracy and the noninclusive modulation of the individual-organization relationship tend to be taken-forgranted. Strange as it may seem at first glance, Foucault's (1977) highly innovative use of panopticon (and the prison) may be taken to suggest total organizations as the model for understanding the modern organizational and institutional order. As indicated by the relevance which monastic life may have assumed for bureaucracy, there exist undeniably affinities in some of the forms and mechanisms by which these two widely differing archetypes of organization assure compliance and construct conformity. However, despite these affinities, bureaucracy and total organizations differ in some substantial ways. Modern discipline in institutional life presupposes the anthropological distinction of the role from the person and the structural device that embeds such a distinction. Without such a separation, the objectification of one's contributions and the self-monitoring along measurable or governable dimensions would be impossible or, at least, hampered substantially. A careful reading of Foucault reenhances this claim (Foucault, 1977, 1980, 1988). The tangle of behaviours, orientations and techniques that constitute humans qua persons must be dissolved to become the target of measurement, examination and control (Hasselbladh and Kallinikos, 2000; Kallinikos, 1996).

\section{Selectivity, Mobility and Reversibility}

Despite its commonsense and, to a certain degree, justified associations with rigid and inflexible behaviour, bureaucracy is the first and perhaps sole organizational form capable of addressing the demands that incessant social, economic and technological change induces. As already suggested, the organizational involvement of individuals qua roles implies the dissociation of the process of organizing from the emotional and cognitive complexity of agents qua persons. By contrast to persons, roles can be adapted, modified, redesigned, abandoned or reshuffled to address the emerging tech- 
nical, social and economic demands the organization is facing. The bureaucratic form can thus shape the contributions of people without demanding basic changes in their personality, other than those related to attitudes and skill mastery. This is precisely accomplished through the detailed design of roles and the rules tied to their performance. In this light, rule-bound behaviour is inter alia motivated by the project of adapting to contingent demands, rather than the other way around, which the conventional understanding of bureaucracy as simply routine seems to suggest. It remains of course a highly delicate issue to which extent organizational and social roles can be severely decoupled from the totality that makes the distinctive mode of being of every human (Tsivacou, 1997). However, both bureaucracy and modern society were built on the premise that such a severe or adequate separation is possible (Mangham, 1995; Sennett, 2000).

The cardinal bureaucratic premise of non-inclusiveness is bound to produce a relationship of the individual to the organization that is marked by selectivity, mobility and reversibility (Gellner, 1983, 1996; Luhmann, 1982, 1995). Selectivity is the outcome of the fundamental relation that individuals assuming organizational roles are expected to suspend non-role demands and act on the basis of a well specified and delimited set of criteria that constitute the role (job description and specification, duties and jurisdictions, field of responsibility). The mobility in the individualorganization relationship is produced by the fact that a role, being an abstract set of functional requirements, can be unleashed from the particular circumstances into which it is embedded, and be transferred across various organizational contexts (Hassebladh and Kallinikos, 2000). Mobility is furthermore enhanced by the reversible terms of individual's involvement in organizations. Reversibility implies that jobs can be altered or redesigned and the organizational sanctioning of job positions modified or even withdrawn. The relationship is also reversible from the point of view of the individual that can invoke several reasons for quitting an organization, even though this may bring negative pecuniary or legal consequences.

Placed on the background of these observations, bureaucracy emerges as an altogether different institution from the conventional image that identifies bureaucratic organizational forms with a sort of behavioural mechanics and incapacity to change. Indeed, the demands of the current age for contingent (local and functionally adaptable), mobile and reversible (temporary) patterns of behaviour cannot but be satisfied by an organization form that strengthens the bureaucratic premises whereby individuals are tied to the organization in terms other than inclusive. Shorter time frames for organizational action, employment forms other than those implied by lifetime contracts, diffuse tasks that demand the constant redesigning of roles, virtual relations, all 
presuppose that individuals are coupled to organizations in terms that are characterized by selectivity, mobility and reversibility.

As construed here the modulation of the individual-organization relationship in selective, mobile and reversible terms represents the cornerstone of bureaucracy. However, while rule-bound behaviour and role specialization can be directly associated with the selective, mobile and reversible terms by which individuals are coupled to organizations, it is not entirely clear how the hierarchical constitution of bureaucracy that represents one of its crucial attributes can be related to these terms. Hierarchy is though a pervasive trans-cultural and trans-historical characteristic that cannot be exclusively attributed to bureaucracy (Dumont, 1967). What is perhaps distinctive in the hierarchical configuration of bureaucratic organization is the relative clear and rule-bound regulation of the exercise of authority. The jurisdictional domain of authority is specified and delimited while its exercise is governed by rules to constitute what Weber (1947) referred to as rational-legal authority. The delimited and rulebound regulation of authority is precisely the outcome of the selective, mobile and reversible terms of modulating the individual-organization relationship. Authority is tied to the office (i.e. the role), exercised upon a specific domain of organizational operations while its organizational sanctioning can be withdrawn at every moment.

The understanding of bureaucracy in the terms described so far represents no doubt but a very concise description of the complex social and cultural processes underlying it. The interpretation of bureaucracy solely in terms by which individuals are tied to organization leaves out of consideration vital social and cultural processes that sustain the bureaucratic form of organization and other modern institutions. It has already been noted that a number of factors contributed to the emergence and diffusion of the bureaucratic organization and the ability to modulate the individualorganization relationship in a non-inclusive fashion. Crucial among them were the decoupling of the social status of individuals from their position in the system of production, the consequent social mobility brought about by bourgeois democracy and the relatively clear separation of private life from the public world. Closely related to these changes were the development of capitalism and market economy. Other crucial factors involved the very anthropological foundations of individualism and the subtle cultural shifts by means of which the world was increasingly understood as the very object of human intentions and calculability and rationality were rendered the universal mode of cognition (Heidegger, 1977). The modulation, therefore, of the individual-organization relationship in selective, mobile and reversible terms evolves within the wider context of a social and cultural universe that we here cannot but take largely for granted. 


\section{The Double Articulation of Bureaucracy}

If bureaucracy is not precisely the rigid organization form commonly assumed then how are we to interpret many contemporary trends that seem to suggest the emergence of forms of organization that depart, in one way or another, from the standard bureaucratic version that dominated modernity? Virtual organization, network models of organization, forms of employment other than those implied by stable, clear-cut job arrangements and lifetime contracts, and flexible production systems can all be invoked as major cases that break with the classical bureaucratic principles of organization. ${ }^{3}$ Do not these examples really suggest bureaucracy to be on the verge of concluding its historical circle?

An important corollary that emerges from the preceding analysis is that standardized behaviour represents a ubiquitous element of all modern organizing that seems unlikely to be suspended by the trends subsumed under such catchwords as network, virtual or entrepreneurial forms of organization. Standardization is essential to all non-haphazard human action and communication that transcend the limits of particular contexts (Hasselbladh and Kallinikos, 2000). As a consequence, organization forms that claim some sort of context independence and universality cannot but exhibit at least a minimum of standardization. A second and perhaps more crucial insight following the analysis undertaken in the preceding pages concerns the relation of standardization to flexibility and the dissociation of bureaucracy from standardization. The bureaucratic form of organization cannot be simply equated with routines and standard operating procedures, no mater how important or ubiquitous they happen to be. Standardized behaviour constitutes the substratum, as it were, by which organizational action is made of. Routines, procedures and roles are the elements of an organizational ars combinatoria capable of constantly reassembling these elements to address the ceaseless emergence of contingencies, underlying the contemporary condition.

The far-reaching consequences of the modular constitution of bureaucracy emerge against the background of the metaphorical associations provided by standardized notation such as alphabetic writing or music notation (Kallinikos, 1996). The ability to bring together the characters of a notational system to various combinations is ultimately dependent on the standardization of every character and its clear distinc-

\footnotetext{
${ }^{3}$ Some other trends that can be tied to the decline of the bureaucratic forms involve the socalled de-institutionalisation of psychiatric care and the care for the disabled and the elderly. However, rather than signifying the end of bureaucracy these trends represent the decline of an organized practice that is by and large associated with total organizations as described in the preceding pages. Indeed, de-institutionalisation in these cases implies that mental patients, disabled and elderly are redefined in terms that transform them from inmates to individuals tied to organizations of the welfare state in selective, mobile and reversible forms. In other words, de-institutionalisation represents a trend toward rather than away from bureaucracy.
} 
tion from other characters. Unless the standardization and finite differentiation of the notational elements of a system are accomplished, no rules can be worked out to govern their combinations (Goodman, 1976). A notational system that is composed of elements that dissolve into their substratum or melt constantly into one another eludes semiosis, and betrays the very purpose that it is supposed to serve (Kallinikos, 1996). Standardization forms a fundamental condition for the huge number of combinations (certainly under a number of constraints) that the standardized elements of a system can enter. Looked upon this way, standardization is a prerequisite for semiotic flexibility. Any system that is based on similar principles of architecture is bound to exhibit behavioural or semiotic flexibility.

To avoid however, the conspicuous logicist associations that could arise from the comparison of organizational action with symbolic notation (Simon, 1969), we could pursue the analogy of bureaucracy with one of the most complex and resilient institutions of social life, namely natural language. The picture of bureaucracy painted in this article suggests that the bureaucratic form of organization could be conceived as being governed by what structuralists once called the principle of double articulation of language. ${ }^{4}$ Like language (phonemes), bureaucracy is composed, at a first level, by a fairly standardized number of elements (e.g. routines, tasks, procedures, roles) that, seen separately from one another, may convey the impression of fixed and limited population of behaviours, devoid of meaning or signification. This is precisely produced by the ability to bring these elements together to various larger patterns (i.e. the second level) that acquire meaning and purpose due to their capacity to respond to emerging social projects. The abstract character of the organizational architecture that coincides with the double articulation of bureaucracy contrasts sharply with the readily observable reality of routines and standardized procedures and may perhaps be held responsible for the widely diffused association of bureaucracy with standardization and rigidification.

The many configurations that can be produced by a system organized in a way resembling the double articulation of natural language provide indeed an indication of the enormous potential such a system disposes for adapting to changing conditions. Through reshuffling and recombination and occasional redesign of its elements the system becomes capable of addressing emerging situations that may demand responses different from those the system has produced so far. Despite the many constraints that may be thought to underlie the combinability of the elements (Kallinikos,

\footnotetext{
${ }^{4}$ The principle of double articulation conceives of language as being composed of two levels. The first level entails those elements of language that lack immediate meaning like phonemes and combinations of phonemes that do not reach the level of word where meaning first appears. Words, sentences, discourses are all meaningful elements whose substratum is made of non-menaningful phomemes (Barthes, 1967; Ricouer, 1977).
} 
1996, 1998) a huge number of combinations are indeed available that may give the organization a broad repertoire of structural and behavioural options. The quest for flexibility cannot therefore be addressed in a genuine fashion unless contemporary forms of organization are built on the very foundations of bureaucracy as outlined in this text. Only by being able to reassemble the standardized elements by which it is made of, to produce new configurations (i.e. products, services, action patterns, etc.), can an organization hope to cope with the constant jumping up of contingencies. A prerequisite for doing so is to allow individuals to be tied to systems in selective, mobile and reversible forms.

The organizational involvement of humans qua roles makes bureaucracy capable of unleashing the process of organizing from the inescapable contextembeddedness of the human body and the intractable complexity of experiences that underlie human beings qua persons. In so doing, it sets the premises for a form of organization free from the restricted mobility of the human body and the languid process of personal and psychological reorientation. Bureaucracy's abstract principles of organization are the hull out of which virtual relations are bound to emerge. Virtual organization is indeed contained as a germ in the very separation of the role from the person, and the design and enactment of action patterns that are only loosely coupled to the corporeality and psychological complexity of humans (Baudrillard, 1983, 1988). The social and psychological conditions necessary for the emergence of bureaucracy give an indication of the profound institutional change necessary to build formal organizations on premises other than those implied by bureaucracy.

The claims advanced so far do not necessarily deny some crucial perhaps differences that seem to be underlying the institutional context (late modernity) into which many organizations currently operate. We mentioned in the introduction several factors (e.g. frequent economic and technological change, individualism and globalization) that distinguish the current environment into which most organizations operate from the asserted stability of bureaucratic contexts. It is a widespread assumption that these factors drive the current shift away from the bureaucratic form of organizations. However, such an assumption makes sense only if bureaucracy is identified with a rigid and inflexible organization form. Placed against the background of the preceding analysis, such an interpretation of the organizational order of modernity emerges as regretfully inadequate. The fast pace and unpredictability of social, economic and technological change make indeed necessary the strengthening or elaboration (rather than the abandonment) of the social and organizational innovations introduced by modernity and bureaucracy. The mobile, selective and reversible relations such innovations promote constitute the sine qua non, the virtual matrix, as it were, out of which concrete instantiations addressing specific set of circumstances emerge. 
There will be certainly occasions of radical environmental change that may require the reinvention and redefinition of the primary organizational substratum of routines, standard operating procedures and roles rather than their sheer recombination. New technologies produce a different segmentation of organizational tasks. This possibility is undeniably present. The comparison of language with forms of organization is, after all, metaphorical. However, in the social realm of organizations, the de novo invention of the entire population of jobs, positions and procedures is a rather rare case and is not supported by empirical facts. Most of the times, novel situations would be possible to cope with a complementary elaboration (elimination or addition of new roles, jobs and procedures) of a basic population of primary elements and the reassembling of these into new configurations. Other times, the comprehensive remaking of the first organizational substratum itself may not have far-reaching implications as it may seem at first glance. The remaking of organizational tasks, roles and procedures in such cases is based on a very similar logic for segmenting and structuring the totality of organizational work. Flexible manufacturing represents a case in point, producing its allegedly customized products through variable standardization of a basic population of components reassembled into final products or services. Contemporary architecture too nowadays produces variable design forms by exploring the possibilities of recombining a population of standardized building components (Kallinikos, 2001).

On the other hand, the shorter time frames of change and the criss-crossing of the organizational horizon by contingencies of various sorts threaten undeniably to shatter the modular constitution of bureaucracy into the very pieces by which it is composed. But it is of utmost important to uphold that the centrifugal forces produced by incessant change arise precisely out of bureaucracy's capacity to respond to the emerging contingencies and not by its inability to act in novel ways.

\section{Constitutive and Variable Characteristics}

The claims advanced so far inevitably lead to the crucial issue concerning the premises by which a system controls itself. Before an organization decides to redefine and reorganise its constitutive elements to produce novel responses to the contingencies it confronts, it needs a mechanism for detecting and handling contingencies. Information must be gathered, processed and transmitted throughout the system. Decisions based on information must be timely made, communicated and transformed to courses of action. Questions of this sort are coped with by means of the distribution of authority and responsibility (centralization). A claim that is often made against the bureaucratic form of organization is that the propagation of information and decisions throughout the system is considerably retarded and often distorted by the hierarchical 
order of bureaucracies. The centralized bureaucratic practices of decision-making and control do not allow for the effective transmission of information while they inhibit initiative taking at the local level. Only a loosely coupled system with multiple loci of control, distributed throughout its various operations, is capable of coping with the sudden turns or contingencies that currently face most organizations (e.g. Heckscher and Donnellon, 1994; Tsoukas, 1996).

There is no doubt that the distribution of control plays an important role in defining a system's behaviour. But again the claim concerning the limited adaptability of the bureaucratic form makes sense on the background of the tacit assumption that bureaucracy is governed by a high and largely invariable degree of centralization. However, the development and very diversity of the modern organizational landscape tells another story. Centralization exhibits a highly variable degree throughout the history of modernity and across the highly differentiated contexts underlying it (see, e.g. Chandler, 1977). Little wonder, similar issues preoccupied organization theorists during the first two or three decades following the Second World War. Various studies document variable degrees of (de)centralization and delegation of authority. Unpredictable contingencies and ambiguous situations lead to decentralized patterns of action and flexible modes of operation (Burns and Stalker, 1961; Perrow, 1967) segmentation and loose coupling (Galbraith, 1973; Simon, 1969; Weick, 1979) and not infrequently to the idiosyncratic patterns of behaviour March and Olsen (1976) summarized with the suggestive term "organized anarchies". It may not have been by accident that none of these authors ever claimed to have discovered the foundations of a new organizational order. Furthermore, de(centralization) takes various forms. Decentralized initiative taking in certain domains may well go hand in hand with centralization in other domains. For instance, operational decisions may well be decentralized while crucial decisions subjected to increasingly tighter control and regulation (Power, 2002). The net outcome of similar patterns are hard to predict and even harder to measure and have their relative significance weighed in empirical contexts.

The fact that formal organizations exhibit a variable centralization suggests that the issue of the distribution of the loci of decisions may be difficult to make the sole criterion for the demise of bureaucracy and the assumed emergence of alternative forms of organization. Neither the issue of centralization-distribution of authority nor that of standardization can be made the yardstick for deciding the limits of the bureaucratic form. No matter how important, these characteristics develop within the constitutive framework of relations established by the non-inclusive forms of human involvement and the selective, mobile and reversible terms by which individuals are tied to organizations. These terms form the very foundation of the bureaucratic organization. They constitute the primary relation out of which other secondary or de- 
rivative characteristics emerge. It is important to uphold the distinction between primary and derivative characteristics. Routines and standardized behaviour and centralization are undeniably important yet derivative characteristics of the bureaucratic organization. They emerge on the very foundation, established by the clear separation of the individual from the organization, and the selective, mobile and reversible terms by which individuals are tied to organizations.

The cardinal importance of the modular, non-inclusive mode for regulating the individual-organization relationship comes forward on the background of another fundamental relation. That is, the non-inclusive mode represents the outcome of a choice that involves a binary alternation (Kallinikos, 1988; Luhmann, 1995; Tsivacou 1997). Either you have an inclusive or non-inclusive mode of regulating the individual-organization relationship. It is impossible or, perhaps more correctly, inconsequential to have little of the former and little of the latter. It may be possible to have different modes regulating separate aspects of an organization but each aspect can be regulated only by one mode. We referred above to total organizations that regulate the life of inmates through an inclusive, non-modular relationship. However, administration in say prisons or mental hospitals is organized according to the non-inclusive, modular relationships and administrative staff occupies and enacts distinctive roles. The selection of either of the two alternatives introduces a code that brings to being a very distinctive mode of organization. By contrast to this binary choice, characteristics like standardization and centralization exhibit a graded intensity. It is always possible to have more or less standardization or centralization. In this sense neither of these characteristics can become the ultimate arbiter for deciding whether an organizational form is bureaucratic or not.

These claims therefore suggest that it is necessary to make a distinction between constitutive and variable characteristics. The non-inclusive mode of human involvement in organizations provides the fundamental condition on the basis of which it is possible to decide whether a form of organization is bureaucratic or not. The significance of variable characteristics, by contrast, develops within the framework established by the constitutive function of the non-inclusive mode of human involvement in organizations. Variable characteristics precisely allow for distinguishing contextual variation of the basic bureaucratic form.

\section{Coda}

The interpretation of bureaucracy suggested in the present article undeniably involves a broad interpretation as to what counts as this organization form. In the final analysis, it tends to identify modernity with bureaucracy. A clear consequence of such an interpretation is to consider the overwhelming majority of formal organizations as bureau- 
cratic, differing only in terms of a number of secondary characteristics such as standardization and centralization.

Broad as it may be, the interpretation of bureaucracy advanced in this article is indeed much closer to the spirit of Weber's work, despite some ambiguity present in his writings, as regards the place and the significance assigned to routine, standardized work (Weber, 1947, 1978). It is even closer to the spirit of the writings of authors that have in one way or another contributed to our understanding of modernity and bureaucracy such as Smith, Marx or even Durkheim. Terms like "division of labour", "exchange value of labour", "abstract or dead labour" "commodification of labour" describe the abstractions of modern conditions of work. They bear strong resemblance to the concepts that were used here to describe the non-inclusive modular foundation of bureaucracy, namely selectivity (division of labour), mobility (commodification of labour) and reversibility (exchange value). The institutionalization of property rights and the expropriation of the workers from the means of production (Marx, 1865, $1867 / 1954,1956)$ is just one expression of the fundamental relations we attempt here to describe with the notion of modular, non-inclusive way of regulating the individual-organization relationship.

The broad interpretation of bureaucracy suggested here is triggered by the alleged prospect of its demise and the current historical junction that seems to be inducing the global re-evaluation of modernity and certain of its key characteristics. The assumption of the conclusion of an age and the decline of its basic forms of organization inevitably prompt the examination of the very foundations on which such forms rest. The present article however suggests that only the substantial redefinition of the core, constitutive properties of bureaucracy that were here identified with the noninclusive forms of human involvement in organizations can really break with the institutional principles bureaucracy embodies and embeds.

Second or late modernity seems at present to provide contradictory signals as to wither it wishes to go. On the one hand, the flexibilization of work moves definitely into the direction of making selectivity, mobility and reversibility even more pronounced than what they have been up to the recent past. On the other hand, there emerge institutional practices that seek to involve individuals in organizations in terms that tend to blur the modern distinction between professional and personal life. Family becomes a burden to professional development while crucial personal characteristics like sexual appeal and attractiveness, reserved once for the realm of intimacy, are increasingly and systematically brought to bear on the accomplishment of organizational objectives. Long hours of work further weaken an already fragile community and public life (Murray et al., 2002). These trends seem to suggest that the boundaries of the institutional separation of the work, family and community that sustained the 
non-inclusive involvement of individuals to organizations tend increasingly to blur (Carnoy, 1992; Sennett, 2000). Elements reminiscent of the inclusive forms of human involvement in organizations re-emerge out of a past that seemed only distant and parochial as late as two decades ago. Some of these trends are analyzed in Kallinikos (2003) but they are of such dignity as to demand a thorough treatment in the future. Perhaps the organization forms and work practices of second modernity will involve combinations that seemed impossible and inconsequential from the horizon of first modernity.

\section{References}

Adorno, Theodore \& Horkheimer, Max (1972) The Dialectic of Enlightment. London:

Verso (originally) published in 1937.

Arendt, Hannah (1958) The Human Condition. Chicago: Chicago University Press.

Arrow, Kenneth (1974) The Limits of Organization. New York: Norton.

Barthes, Roland (1967) Elements of Semiology. New York: Noonday.

Beniger, James (1986) The Control Revolution: Technological and Economic Origins of the Information Society. Cambridge, Mass: Harvard University Press.

Baudrillard, Jean (1983) The Ecstasy of Communication, in H. Foster (ed.), The AntiAesthetic:Essays in Postmodern Culture. Port Townsend: Bay Press.

Baudrillard, Jean (1988) Selected Writings. Stanford: Stanford University Press.

Bauman, Zygmut (1992) Intimations of Postmodernity. London: Routledge.

Beck, Ulrich (1992) Risk Society: Towards a New Modernity. London: Sage

Beck, Ulrich (2000) The Brave New World of Work. Cambridge: Polity.

Braverman, Harry (1974) Labour and Monopoly Capital. New York: The Monthly Review Press.

Burns, Tom \& Stalker, George (1961) The Management of Innovation. London: Tavistock.

Carnoy, Martin (2000) Sustaining the New Economy: Work, Family and Community in the Information Age. Cambridge, Mass: Harvard University Press.

Castells, Manuell (1996) The Rise of Network Society. Oxford: Blackwell.

Castells, Manuell (2001) The Internet Galaxy. Oxford: Oxford University Press.

Castoriadis, Cornelius (1987) The Imaginary Institution of Society. Stanford: Stanford University Press.

Castoriadis, Cornelius (1985) The Bureaucratic Society: Two Volumes. Athens: Ypsilon.

Chandler, Alfred, D. (1977) The Visible Hand: The Managerial Revolution in American Business. Cambridge, Mass: Harvard University Press,

Ciborra, Claudio (ed.) (2000) From Control to Drift: The Dynamics of Corporate Information Infrastructures. Oxford: Oxford University Press.

Clegg, Stewart (1994) 'Weber and Foucault: Social Theory for the Study of Organizations', 
Organization 1/1: 149-178.

Coase, Ronald (1937) 'The Nature of the Firm', Economica 4: 386-405.

Du Gay, Paul (1994) 'Colossal Immodesties and Hopeful Monsters', Organization, 1/1:

125-148.

Du Gay, Paul (2000) In Praise of Bureaucracy: Weber, Organization, Ethics. London: Sage.

Dumont, Louis (1967) Homo hierarchicus: le Systeme des castes et ses implications. Paris:

Gallimard.

Fukuyama, Francis (1997) The End of Order. London: Centre for Post-collectivist Studies.

Foucault, Michel (1977) Discipline and Punish. London: Penguin.

Foucault, Michel (1980) Power/Knowledge. Edited by C. Gordon. New York: Pantheon.

Foucault, Michel (1988) 'Technologies of the Self', in L. H. Martin, H. Gutman and Hutton,

P. H.(eds.) Technologies of the Self, 16-49. London: Tavistock.

Galbraith, Jay (1973) Organization Design. Reading, Mass: Addison-Wesley.

Gellner, Ernst (1983) Nations and Nationalism. Oxford: Blackwell.

Gellner, Ernest (1996) Conditions of Liberty: Civil Society and its Rivals. London: Penguin.

Goodman, Nelson (1976) Languages of Art. Indianapolis: Hackett.

Goffman, Erving (1961) Asylums. London: Penguin.

Hall, Richard (1982) Organizations: Structure and Processes. Englewood Cliffs, NJ: Prentice Hall.

Hanseth, Ole (2000) 'The Economics of Standards' in Ciborra, C. (ed.) (2000) From Control to Drift: The Dynamics of Corporate Information Infrastructures. Oxford: Oxford University Press.

Harrison Bennett (1994) Lean and Mean. New York. Basic Books

Hasselbladh, Hans \& Kallinikos, Jannis (2000) 'The Process of Rationalization: A Critique and Re-appraisal of Neo-institutionalism in Organization Studies', Organization Studies, 21/4; 697-620.

Hayek, Frederick (1960) The Constitution of Liberty. London: Routledge.

Heckscher, Charles \& Donnellon, Anne (eds) (1994) The Post-Bureaucratic Organization. London: Sage

Heidegger, Martin (1977) The Question Concerning Technology and Other Essays. New York: Harper.

Kallinikos, Jannis (1996) Technology and Society: Interdisciplinary Studies in Formal Organization. Munich: Accedo.

Kallinikos, Jannis (1998) 'Organized Complexity: Remarks on the Technologizing of Intelligence', Organization, 5/3: 371-396.

Kallinikos, Jannis (2001) In the Age of Flexibilility: Managing Organizations and Technology. Lund: Academia Adacta.

Kallinikos, Jannis (2003), 'Work, Employment and Organization Forms: An Anatomy of 
Fragmentation, Organization Studies (forthcoming).

Kling, Rob (ed.) (1996) Computerization and Controversy: Value Conflicts and Social

Choices. San Diego: Morgan Kauffman, Second Edition.

Lackoff, George (1995) ‘Body, Brain and Communication', in Brook, J. \& Boal, I. A. (eds.), Resisting the Virtual Life. San Francisco: City Lights.

Luhmann, Niklas (1982) The Differentiation of Society. New York: Columbia University Press.

Luhmann, Niklas (1995) Social Systems. Stanford: Stanford University Press.

Luhmann, Niklas (1996) 'Complexity, Structural Contingency and Value Conflicts' in Heelas,Paul, Scott, Lash \& Morris, Paul (eds.) Detraditionalization. Oxford. Blackwell.

Mangham, Iain L., 'MacIntyre and the Manager', Organization, 2(2): 181-204.

March, James, G. and Olsen, Johan, P. (1976) Ambiguity and Choice in Organizations.

Oslo: Universitetsfoerlaget.

Marcuse, Herbert (1955) Eros and Civilization. Boston: Beacon Press.

Marx, Karl (1954 \& 1956) The Capital. Two Volumes. Moscow: Progress Publishers. Originally Published in 1865 and 1867 respectively.

Mumford, Lewis (1934) Technics and Civilization. London: Harvest/HBJ.

Murray, Gregor, Belanger, Jacques, Giles, Anthony and Lapointe, Paul-Andre (2002) Work and Employment Relations in the Hich-Performance Workplace. London: Continuum.

Noble, David (1984) Forces of Production: A Social History of Industrial Automation. New York: Alfred, A. Knopf.

Perrow, Charles (1967) A Framework for the Comparative Analysis of Organizations, American Sociological Review, 32/2 194-208.

Perrow, Charles (1986) Complex Organizations: A Critical Essay. New York: Random House, Third Edition.

Power, Mike (2002) The Invention of Operational Risk, talk held at the Department of Information Systems, LSE, 29 May 2002.

Pugh, Derek, Hickson, David et al. (1963) 'A Conceptual Scheme for Organizational Analysis', Administrative Science Quarterly, 8: 289-315.

Pugh, Derek, Hickson, David et al. (1968) 'Dimensions of Organizational Structure', Administrative Science Quarterly, 13: 65-104.

Ricouer, Paul (1977). The Rule of Metaphor: Multidisciplinary Studies in the Creation of Meaning in Language. Toronto: Toronto University Press.

Rifkin, Jeremy (1995) The End of Work. New York. Putnam.

Rifkin, Jeremy (2000) The Age of Access. London: Penguin.

Scott, Richard (1981) Organizations: Rational, Natural and Open Systems. Englewood Cliffs, 
NJ: Prentice Hal

Sennett, Richard (1992) The Fall of Public Man. New York: Norton.

Sennett, Richard (2000) The Corrosion of Character: The Personal Consequences of Work in the New Capitalism. New York: Norton.

Seyer, Derek (1991) Capitalism and Modernity: An Excursus of Marx and Weber. London: Routledge.

Simon, Herbert, A. (1969) The Sciences of the Artificial. Cambridge, Mass.: The MIT Press.

Tsivacou, Ioanna (1997) With the Eye of the Observer: Description and Design of Social

Organizations. Athens: Themelio (in Greek).

Tsoukas, Haridimos (1996) 'The Firm as Distributed Knowledge System: A Constructionist Approach', Strategic Management Journal, 17: 11-25

Weber, Max (1947) The Theory of Social and Economic Organization. London: Free Press.

Weber, Max (1970) From Max Weber. London: Routledge. Edited by Gerth, H. \& C. Wright Mills.

Weber, Max (1978) Economy and Society, two volumes. Berkeley: University of California Press. Edited by Roth, G. \& Wittich, C.

Weick, Karl E. (1979) The Social Psychology of Organizing. Reading, Mass: Addison Wesley.

Williamson, Oliver (1975) Markets and Hierarchies. New York: Free Press.

Womack, James, P. and Jones, Daniel (1996) Lean Thinking. New York: Simon \& Schuster.

Zuboff, Soshana (1988) In the Age of the Smart Machine. New York: Basic Books. 